\title{
False Twisting of a Staple Yarn in a Potential Dyeing Process
}

DOI:

10.1080/00405000108659562

\section{Document Version}

Accepted author manuscript

Link to publication record in Manchester Research Explorer

\section{Citation for published version (APA):}

Cork, C., Foster, P. W., \& Oulton, D. (2009). False Twisting of a Staple Yarn in a Potential Dyeing Process. Textile Institute. Journal, 92(2), 115-126. https://doi.org/10.1080/00405000108659562

\section{Published in:}

Textile Institute. Journal

\section{Citing this paper}

Please note that where the full-text provided on Manchester Research Explorer is the Author Accepted Manuscript or Proof version this may differ from the final Published version. If citing, it is advised that you check and use the publisher's definitive version.

\section{General rights}

Copyright and moral rights for the publications made accessible in the Research Explorer are retained by the authors and/or other copyright owners and it is a condition of accessing publications that users recognise and abide by the legal requirements associated with these rights.

\section{Takedown policy}

If you believe that this document breaches copyright please refer to the University of Manchester's Takedown Procedures [http://man.ac.uk/04Y6Bo] or contact uml.scholarlycommunications@manchester.ac.uk providing relevant details, so we can investigate your claim.

\section{OPEN ACCESS}




\title{
False Twisting of a Staple Yarn in a Potential Dyeing Process
}

\author{
C.R. Cork*, P.W. Foster, and D.P. Oulton \\ Department of Textiles, UMIST, Manchester M60 IQD, UK \\ (*Corresponding author: colin.cork@umist.ac.uk)
}

Received 19.3.1998 Received in revised version 21.3.2001 Accepted for publication 28.11.2001

\begin{abstract}
A previously developed, environmentally friendly method of continuous dyeing of filament polyester yarn used technology based on the Fibre-M constant bulk texturing system. This paper describes some progress towards modifying aspects of this technology to facilitate processing of staple yarns as a precursor to developing a dyeing process for staple yarn based on the technology. Originally, the high-pressure steam input to the system caused instant breakages in staple yarns. However, by the introduction of a false-twist jet, modest running times have been achieved. The next step is to apply the new technology in an actual dyeing process.
\end{abstract}

\section{INTRODUCTION}

The development of clean technology is of increasing importance. The textile and clothing industry has serious effluent problems that must be addressed. Current dyehouse practices do not meet, or only meet with great difficulty, the legal requirements for effluent discharges. There is, therefore, a need for a new approach.

The majority of apparel textile materials are dyed. The two most important methods are piece (i.e. fabric) dyeing and yarn dyeing. In both cases expensive clean up plants have to be installed at dyehouses before the large volumes of water involved in dyeing can be discharged. Piece dyeing has the advantage of greater flexibility in response to the market and the economic advantage of adding value at a later stage of production. In general, however, piece-dyed fabrics have only one colour, whereas fabrics woven from dyed yarn can be designed to produce pleasing effects. Dyed yarn is, therefore, an important element in textile production. It is generally used in the manufacture of more expensive fabrics. For example, in suiting fabrics and upholstery a preponderance of dyed yarns is used.

With both commercial and environmental pressures, there has been considerable research activity into new dyeing methods, and numerous novel approaches to the problem have been suggested with various levels of success.

One particularly promising development in recent years is the method described by Saus et al. (1993) and Knittel and Schollmeyer (1995), where supercritical fluids, particularly carbon dioxide, are used as a dyeing medium. This method offers the prospect of completely environmentally friendly dyeing of textiles, but has the disadvantage that it is currently a batch process.

In the area of continuous yam processing. Niederhauser et al. (1973) have developed a method of padding dye on yarm using compressed air cells to impregnate and then squeeze the dyed yarn. A patent filed by Fleissener et al. (1972) describes a continuous method of dyeing yarn or similar material by spray application of dye. Hardalov and Mikhaylova (1993) describe a method of continuous dyeing and bulking of acrylic yarns. 
In addition, Rhone Poulenc (1973) have developed a system for texturing and dyeing yarn using hot fluid flow into a yarn that has been stacked and compressed into a confined space by steam pressure. The latter is related to the Fibre-M system, but differs in that yarn texturing is produced by compaction rather than by turbulent flow.

An alternative, well established, approach is to add pigments as synthetic fibres are extruded. At various times manufacturers have offered ranges of spun-dyed nylon, acrylics, polypropylene, etc. As far as dye waste is concerned, these processes are environmentally friendly. In the main, however, such products have found only small market niches where the colour fastness of the pigment, relative to a dyestuff, outweighs the main disadvantages that are inherent in the method. Firstly, the range of colours that even the largest manufacturer can produce is restricted by the difficulty in changing colours. To clean a machine, fibre must be spun to waste for several hours. Secondly, dyeing occurs early in the transformation of fibre to garment. Generally it is best to add value at a later stage of any process in order to minimise costs and produce market flexibility. Accordingly, while spun-dyed fabrics bave a place in the market (for example, for light fastness in automobile fabrics), their applications are very limited. Thus, for today's industry the yarn dyed route remains very important.

Chowdhury (1992) has developed an environmentally friendly method for the continuous dyeing of yarn using equipment similar to the Fibre-M yarn texturing system originally developed by Foster (1975). However, in the original Fibre-M system, the height of a hot yam plug injected by steam into a cooling chamber is used to provide feedback to control the steam input temperature. The plug height reflects the level of yam bulk and the related steam temperature thus controls the level of texturing. In Chowdhury's system, the hot yam plug is used to achieve dyeing and fixing of yam during a slow moving stage of a fast moving yarn process, rather than to provide feedback. Steam at constant temperature and pressure is used to form the plug.

As a continuous process, Chowdhury's method has more in common with chemical engineering techmiques than many traditional dyeing practices. The process was designed around textured polyester, recognising that, of the synthetic fibres, polyester is used in the largest quantity in apparel fabrics. The method proved unsuitable for staple fibre yarns because the yarns broke in the jet. This imposed serious limitations on the system at a time when there was an increasing trend towards a preference for natural fibres and natural fibre blends. This paper describes progress towards widening the scope of Chowdhury's original filament polyester method to the wider set of fibre combinations that processing of staple fibre yarns would allow. The aim of work reported here was to investigate methods of mechanically processing staple yarns on a Fibre-M system.

\section{NEW DEVELOPMENTS}

The Fibre-M system was designed to texture filament yam using a turbulent steam jet. However, even after removal of the turbulent jet, the steam inlet still presents a harsh environment for the staple yarn. A schematic of Chowdhury's apparatus for dyeing filament yarn is shown in Fig. 1. Yarn enters at the base of the apparatus through a set of labyrinth seals at $A$. The labyrinths take the form of small chambers connected by a collinear set of fine holes through which the yarn can pass freely. Superheated steam at approximately 6 bar is introduced to the system at $B$, a point just above the seals. As the labyrinths restrict the flow of steam downwards, the steam is directed upwards driving the yarn along in this direction. The yam is formed into a plug at $C$. The plug former reduces the upward momentum of the steam by allowing it to escape sideways through a set of 


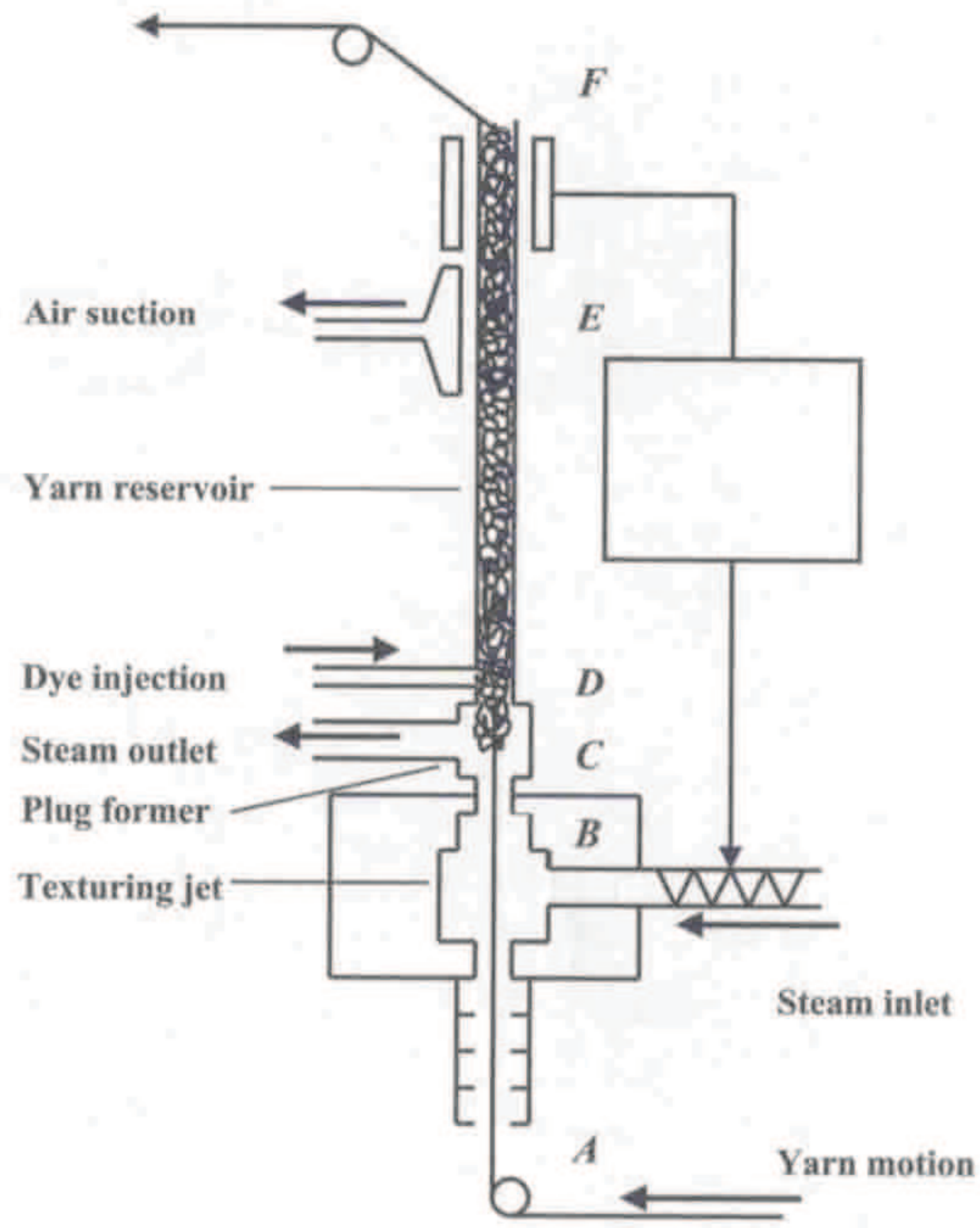

Fig. 1 Chowdhury's system for the continuous dyeing of yam

slots. The inner edges of these slots form a small basket-like chamber where the hot plug is formed. The hot plug is then introduced into the yarn reservoir $(D-F)$. Dye is added in droplet form (Chowdhury, 1992) at the base of the reservoir and the plug is cooled by sucking air through the yam reservoir at $E$.

Early attempts to run staple yarn on this system were unsuccessful. Staple yarn failed either instantaneously or after a few seconds. Analysis of the broken yarn suggested that coherence due to twist is disrupted. In an attempt to solve the problem, two versions of the plug forming assembly (Fig. 2) were investigated. Assembly II is similar to assembly I, the original used by Chowdhury, but has a larger sized input orifice designed to improve steam flow in the direction of motion of the yarn. Furthermore, in order to improve the stability of yarns in the region of the steam inlet, a twist jet was designed. The rationale was to introduce false twist to give additional cohesion to staple yam between the input labyrinth and the point of steam injection.

The twist jets were designed to fit into the pre-heat chamber below the plug forming assembly (Fig. 3). Three twist jets, differing in the configuration of the steam inlet channels, were designed and built. Jet $\mathrm{A}$ has three tangential inlets set at $50^{\circ}$ to the yarn 


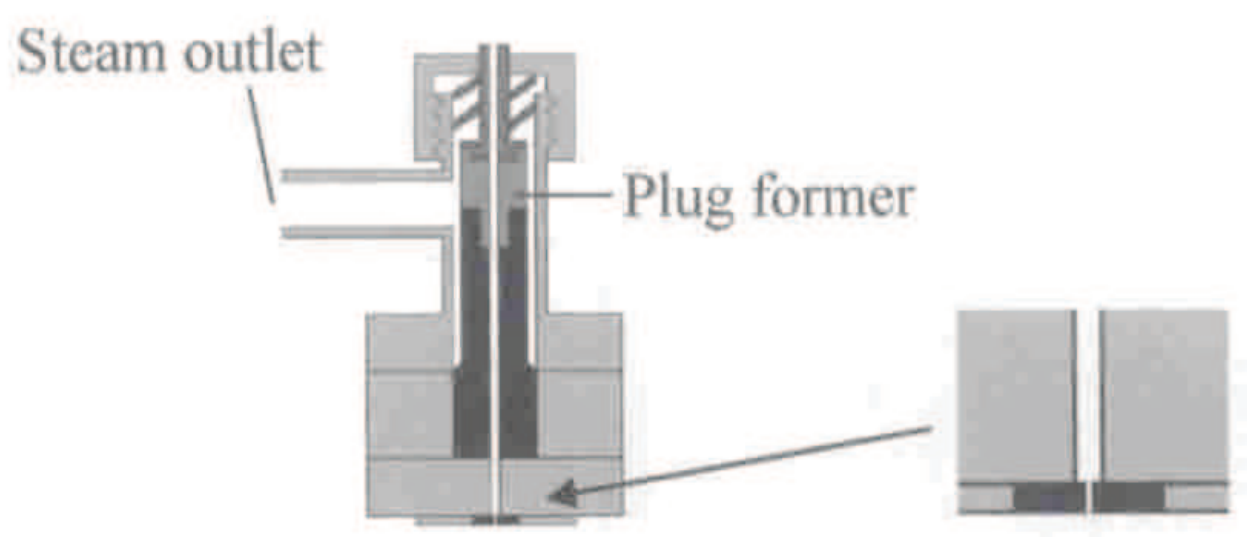

a) Assembly 1

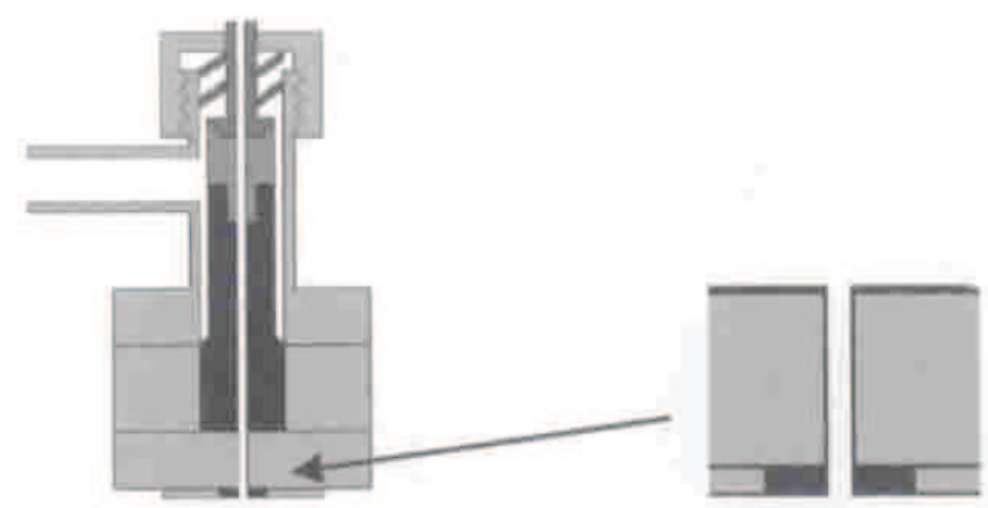

b) Assembly II

Fig. 2 Plug forming assemblies (inset show details of yarn entry points)

axis (Fig. 4). The angle chosen was based on a jet described by Oxenham and Basu (1993). The jet imparts an anticlockwise twisting action as viewed from a point downstream of the yam. Jet B is similar to jet A but twists in the opposite direction. Jet C (Fig. 5) has radial jets and was designed to insert no twist and thereby act as a control. From geometric considerations it can be deduced that, for the $\mathrm{Z}$ twisted yam tested, the action of jet $\mathrm{A}$ is to add $\mathrm{Z}$ twist yam upstream of the jet, whereas jet $\mathrm{B}$ would be expected to reduce or reverse twist for the same yarn in this region. However, the mechanics of the precise distribution of twist along a running yarn in the region of an enclosed air jet twister is not well understood. For example, the twisting vortex might extend in both directions to regions well outside the point of steam injection.

\section{YARNS}

A range of commercial filament polyester, filament nylon, staple polyester/cotton and staple cotton was procured for trials. Table I lists the staple yams tested on the new 


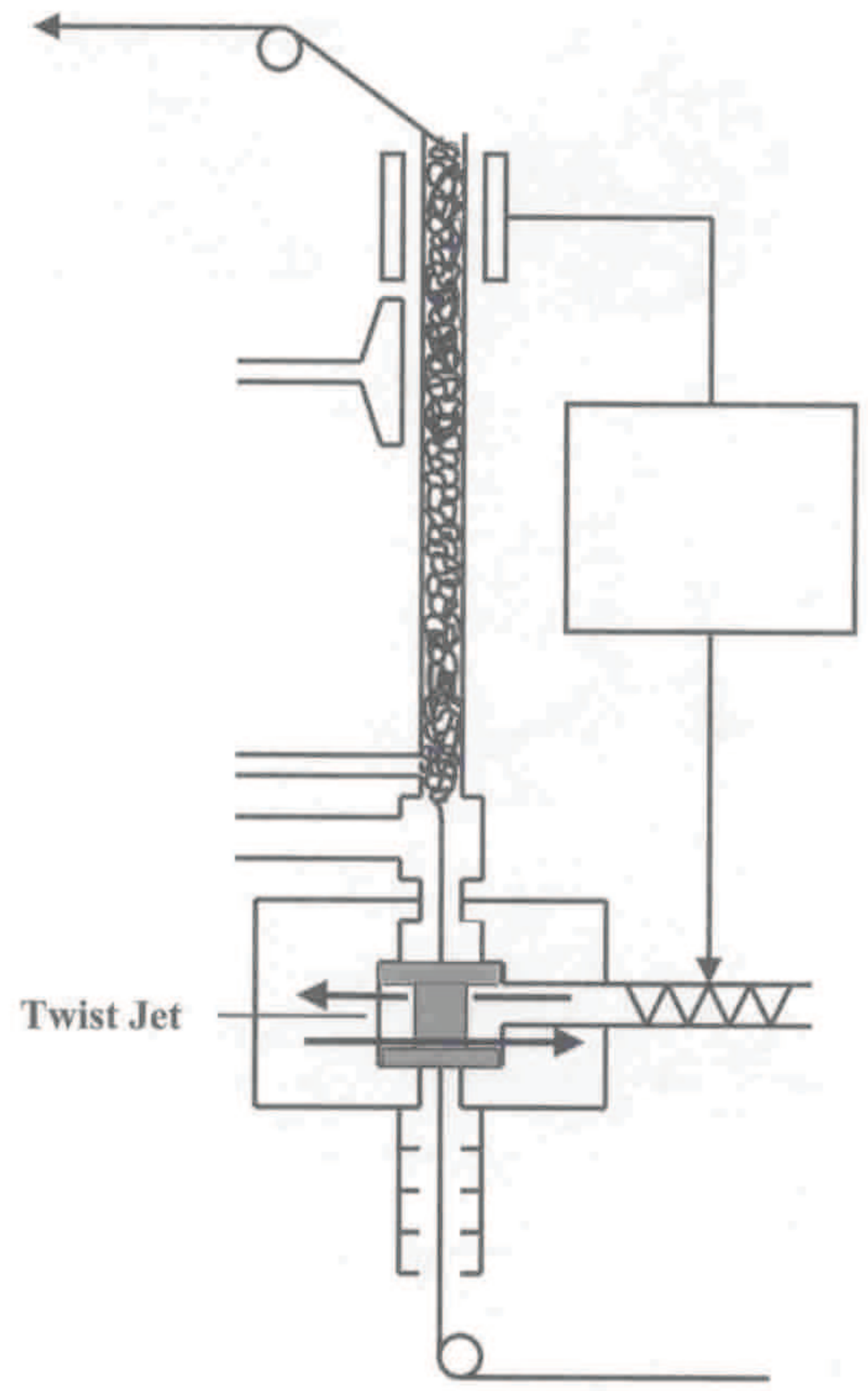

Fig. 3 The location of the twist jet

system. The linear density, twist level, tenacity and elongation at break of these yarns are shown in the table,

An important factor in processing staple yarn on the new system may be the stability of the yarn when locally untwisted by the turbulence of the steam input. Geometrically, open-end spun yarns cannot be fully untwisted by homogeneous rotation as there is generally a large difference between the twist of the wrapping fibres and that of those in the core. In order to determine the stability of a selection of yarns, the tensile strength 


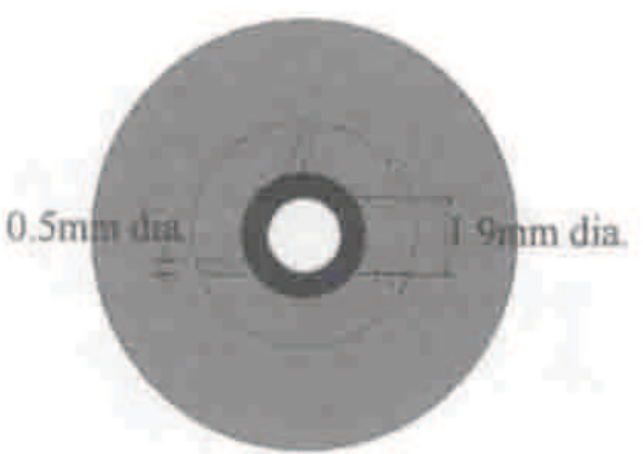

TOP

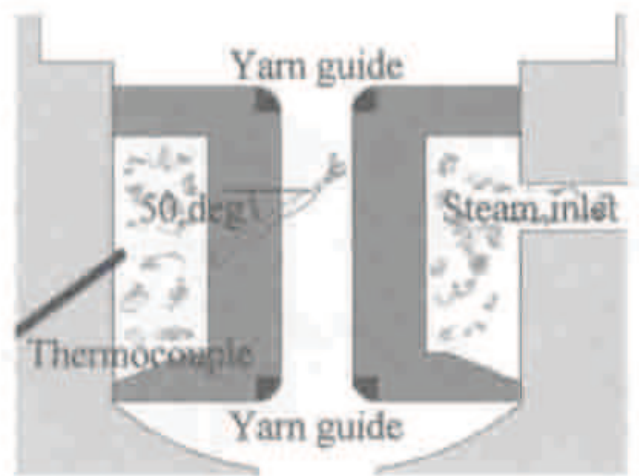

SECTION

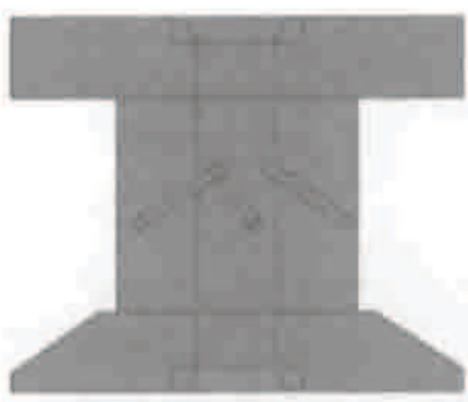

SIDE

Fig. 4 Twist jet A (Twist jet B has the same configuration but with the opposite handedness)

was measured after the twist had been either inserted (+ve values) or removed (-ve values). Typical results for an extended range of yarns are shown in Fig. 6 . The ring spun cotton and polyester/cotton yarns tested had zero residual strength whereas the open-end spun cotton and polyester/cotton yarns had residual strengths between 0.2 and $8.0 \%$ and between 17.8 and $75.6 \%$ of their original strengths, respectively. The highest retention of strength was for the yam PC8 (Fig. 7).

\section{PROCESSING STAPLE YARN ON THE NEW SYSTEM}

Trials were performed to observe the effects of different plug forming assemblies, twist jets and yarns, on the processing of staple yarn and on plug formation.

The runnability of yarn through the system without plug formation was investigated. As expected, filament polyester yarns could be processed without adaptation. In contrast, a ring spun polyester/cotton staple yam (PC1) failed almost immediately with the system in its original configuration or with jets $B$ and $C$ installed. However, with jet $A$, the yam could be processed for up to $20 \mathrm{~min}$ (Fig. 8) before failure occurred.

With jet $\mathrm{A}$ installed, failure occurred in the region downstream of the apparatus. This may be connected with the level of residual twist in the yarn. Although the exact region of false twist may be poorly defined for a jet twister, it is clear that the overall twist change generated by any false twist process must be zero. Nevertheless, if the twisting rate varies, fluctuations in output twist are generated. It is common knowledge that jet vortex twisting systems give rise to varying rates of twisting and tests have shown that 

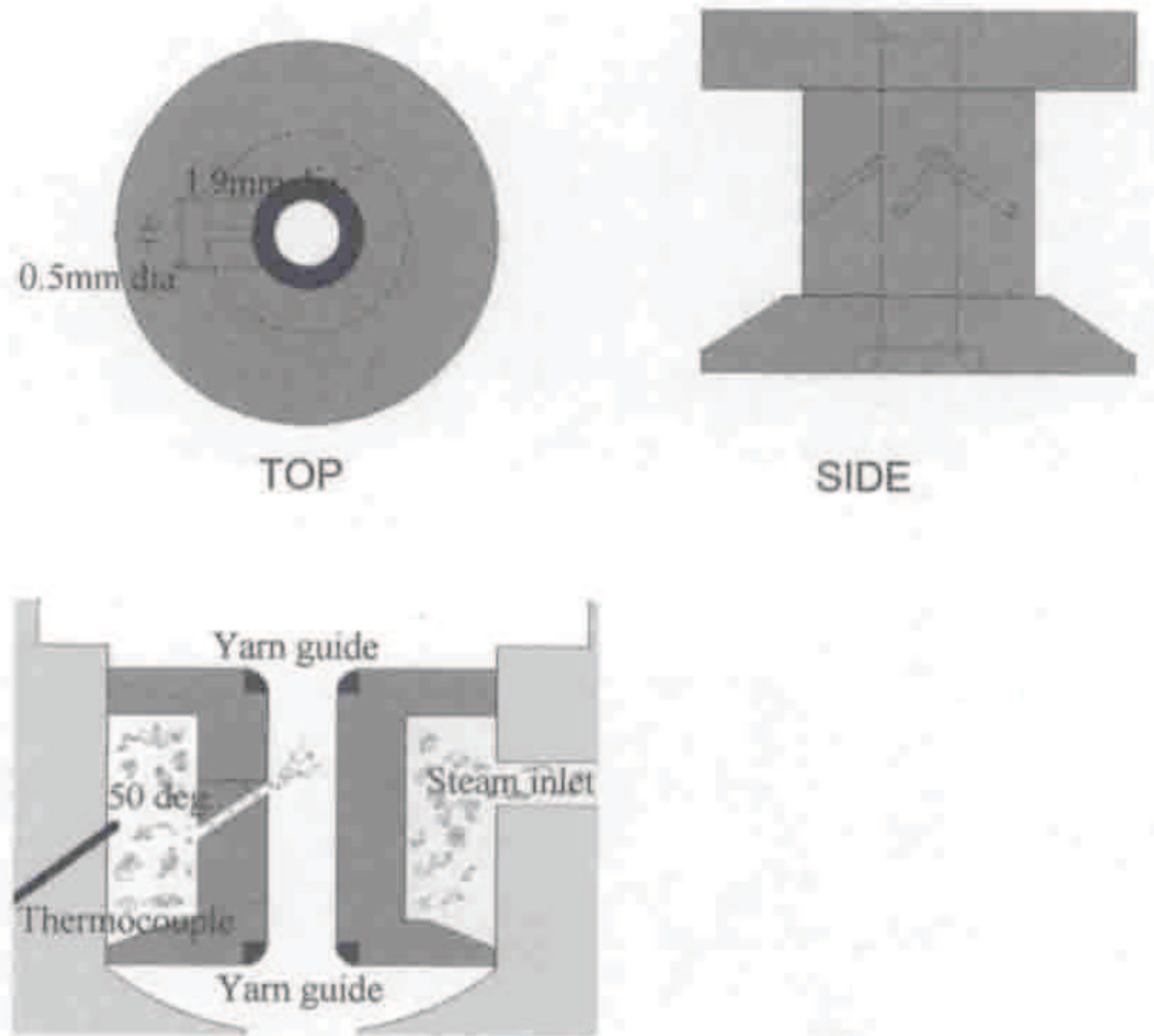

\section{SECTION}

Fig. 5 Twist jet $\mathrm{C}$

Table I

Details of Staple Yarns

\begin{tabular}{lcccccccc}
\hline Code & Fibre & Blend & $\begin{array}{c}\text { Spinning } \\
\text { Method }\end{array}$ & $\begin{array}{c}\text { Linear } \\
\text { Density } \\
\text { (tex) }\end{array}$ & $\begin{array}{c}\text { Twist } \\
\text { Level } \\
(\mathrm{Z}) \\
\text { (turns/m) }\end{array}$ & $\begin{array}{c}\text { Tenacity } \\
\text { (Uster } \\
\text { Tester) } \\
(\mathrm{CN} \text { per tex })\end{array}$ & $\begin{array}{c}\text { Elongation } \\
\text { (Uster } \\
\text { Tester) } \\
(\%)\end{array}$ & Source \\
\hline C4 & Cotton & 100 & Open end & 30.1 & 652 & 12.6 & 7.87 & UMIST \\
PC1 & Polyester/cotton & $50 / 50$ & Ring & 14.6 & 925 & 18.2 & 7.67 & Company A \\
PC6 & Polyester/cotton & $67 / 33$ & Open end & 29.5 & 295 & 18.0 & 10.46 & Cormpany B \\
PC8 & Polyester/cotton & $50 / 50$ & Open end & 29.7 & 433 & 15.8 & 9.50 & Company C \\
\hline
\end{tabular}

such fluctuations occur in yarn taken from a region immediately downstream of the plug former. With no twist jet present, the twist fluctuations in yarn from the original package and after processing were very similar [Fig. 9(a)]. However, when twist jet A is installed, large variations in residual twist are produced [Fig. $9(b)$ ]. For the filament yarn this creates no loss of strength but, for staple yarn, it may result in serious weaknesses downstream of the new system.

The combined results for yarns $\mathrm{PCl}$ and $\mathrm{PC} 6$ using plug forming assemblies I and II and jets A, B and C are shown in Fig. 10. Plug forming assembly II may contribute to a slight improvement when running yam PC6. However, the greatest contribution to improved processing was made by jet $\mathrm{A}$, which added twist to the original yam twist rather than removing or reversing it. 


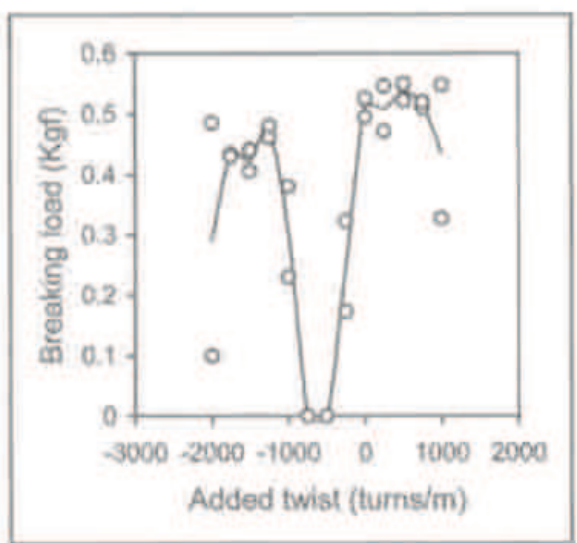

Ring spun cotton

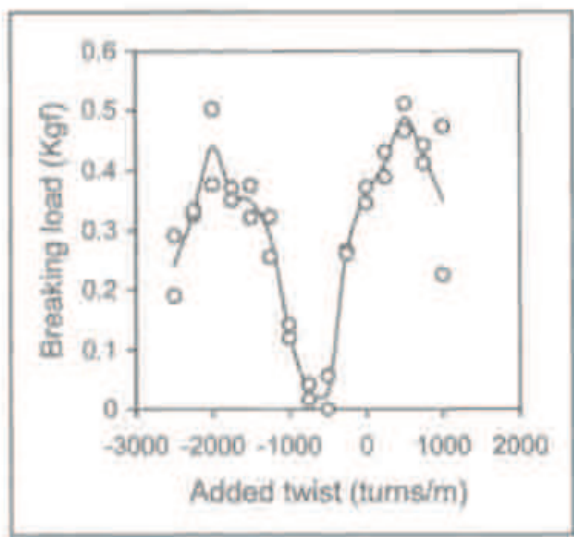

Open end cotton

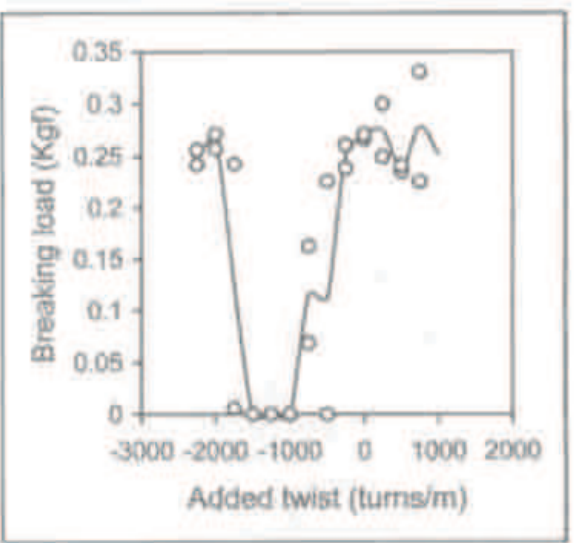

Ring spun polyester/cotton

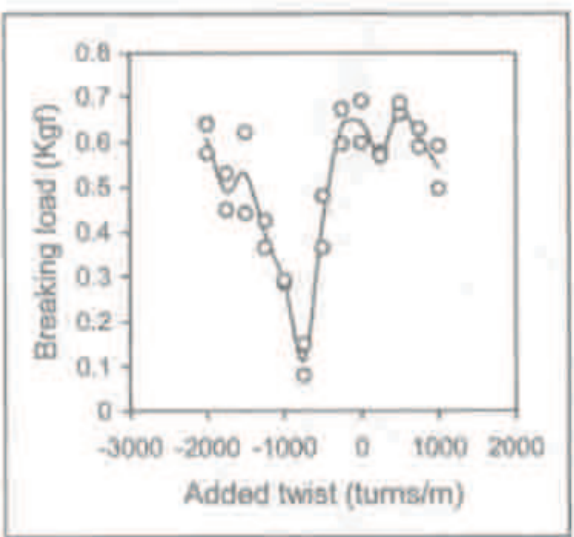

Open end polyester/cotton

Fig. 6 Variation of yarn strength with added twist

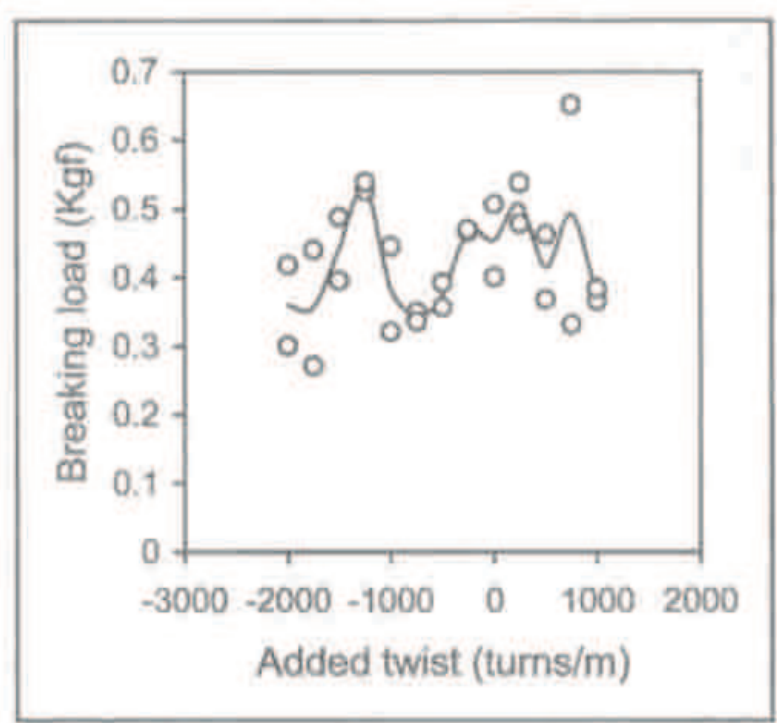

Fig. 7 Variation of yarn strength with added twist for yam PC8 


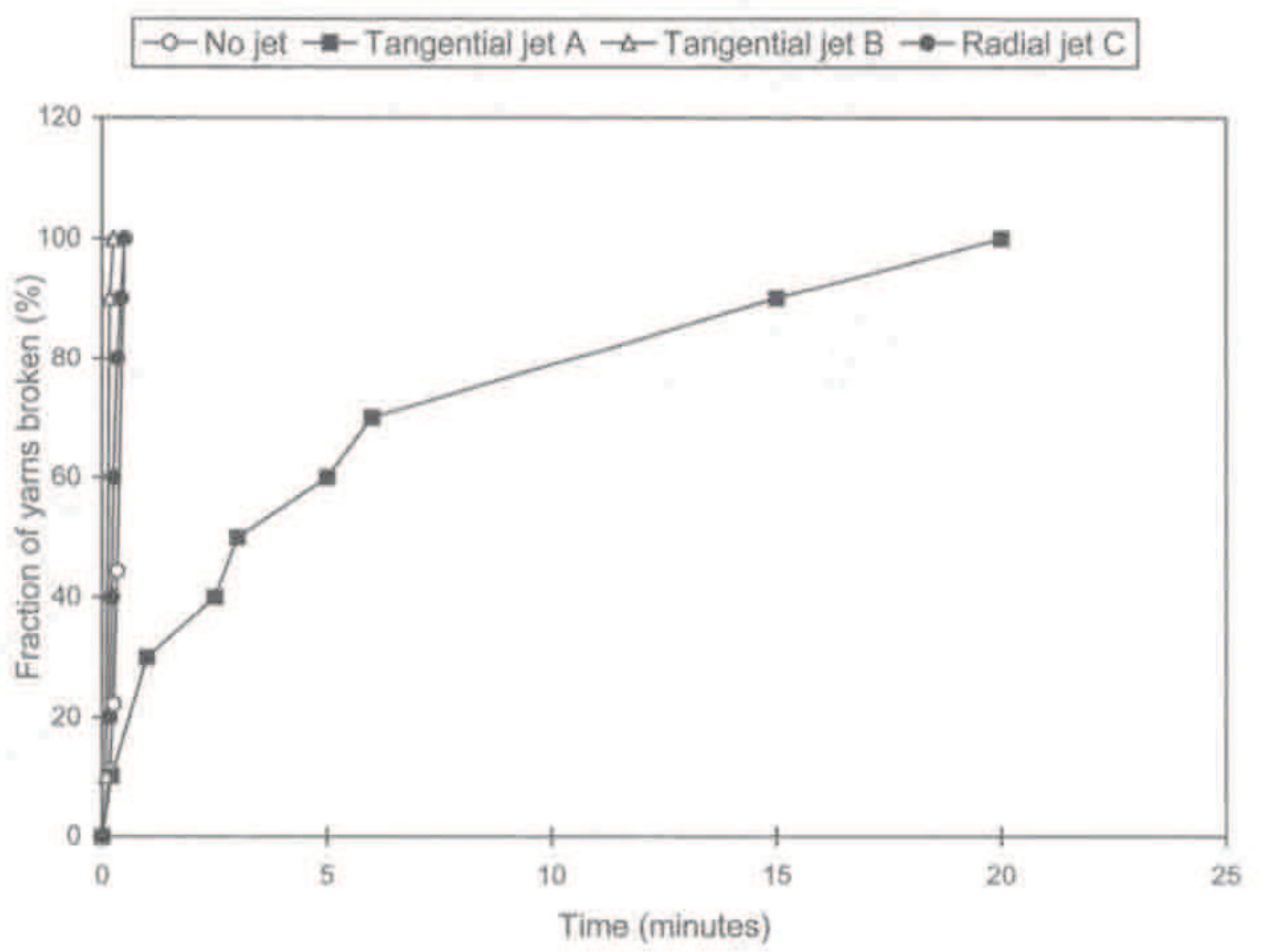

Fig. 8 Effect of twist jet design on survival of a $50 / 50$ polyester/cotton yam

In order to identify the effects of the type of yarn on runnability, four yarns were run under identical conditions. Fig. 11 shows the results for PC1, PC6, PC8 and C4 using twist jet $\mathrm{A}$ and plug forming assembly $\mathrm{I} . \mathrm{PCl}$ is ring spun and $\mathrm{PC} 6$ and $\mathrm{PC} 8$ are open-end spun. All the yarns exhibit extended running times but the longest survival times, by far. are for yarn PC8. Yarn PC8 can be run either with no twist jet or with the reverse twist jet, although greater run times were achieved with jet A. Yarn PC8 is not particularly strong nor is its twist level particularly high (Table I). However, this yarn showed the lowest loss of strength after untwisting (Fig. 7).

In addition to trials on the runnability of yarn through the system jet, nylon, polyester and polyester/cotton yarns were tested for plug formation. All formed satisfactory plugs but there remain some problems with the free movement of plugs for the polyester/cotton yarns. On occasions plug formation was temporarily stopped. The plug could be restarted by reducing the plug height to zero but, obviously, a continuous plug formation is required if the system is to have practical applications.

\section{CONCLUSIONS}

The feasibility of processing staple yarn on the system for the continuous dyeing of yarn has been demonstrated. The problem of instantaneous failure of staple yarn has been greatly reduced and plug formation has proved possible.

Both cotton and polyester/cotton yams have been successfully processed in the rig without immediate failure as a result of the effects of the steam inlet jet. Twist jet A (added twist) prolongs running times but twist jet B (subtracted twist) offers no advantage over the 'no jet' configuration. The result demonstrates that the success of twist jet $\mathrm{A}$ is due to additive twist insertion and not to the tangential configuration of the inputs, as jet $\mathrm{B}$ also has an identical 


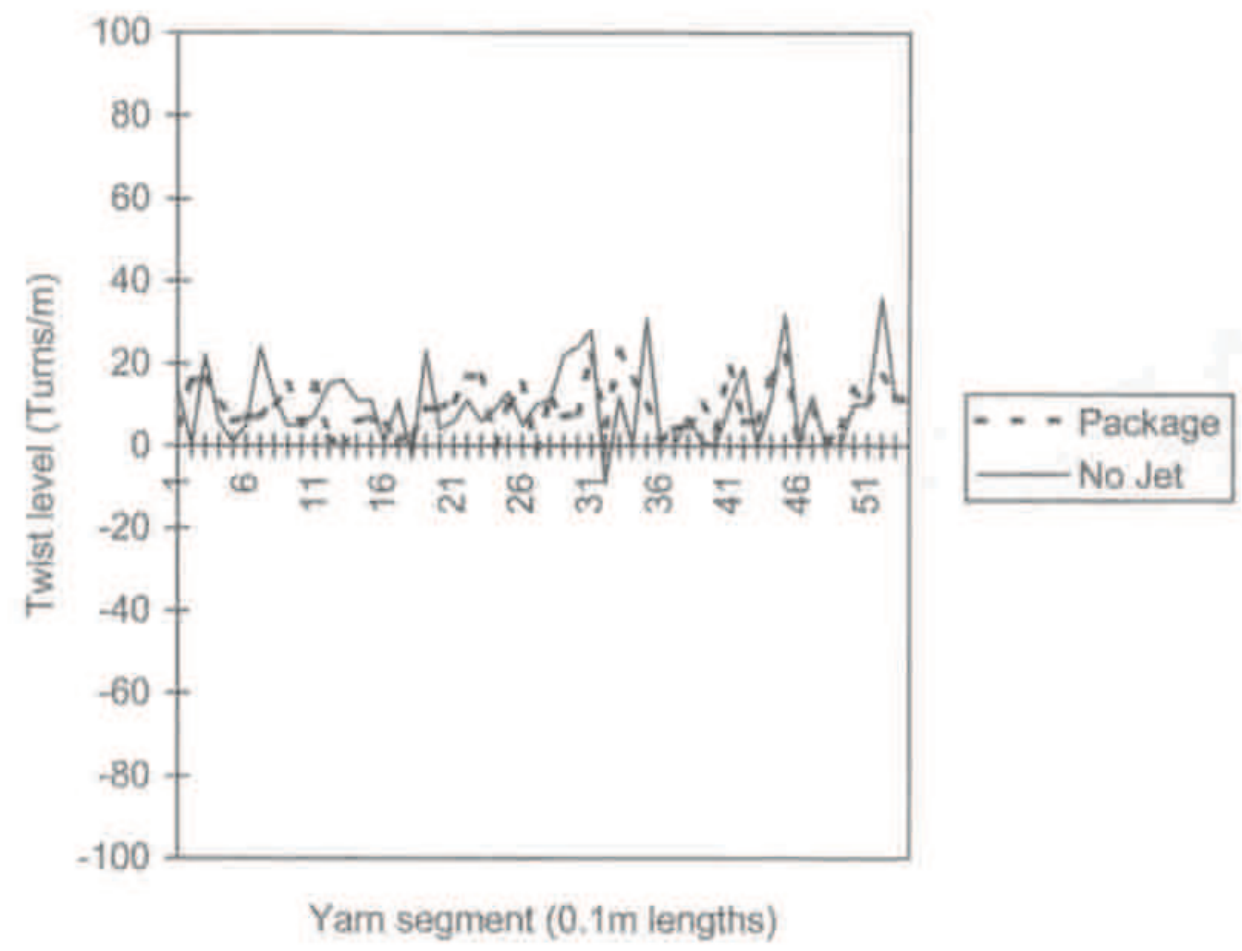

(a)

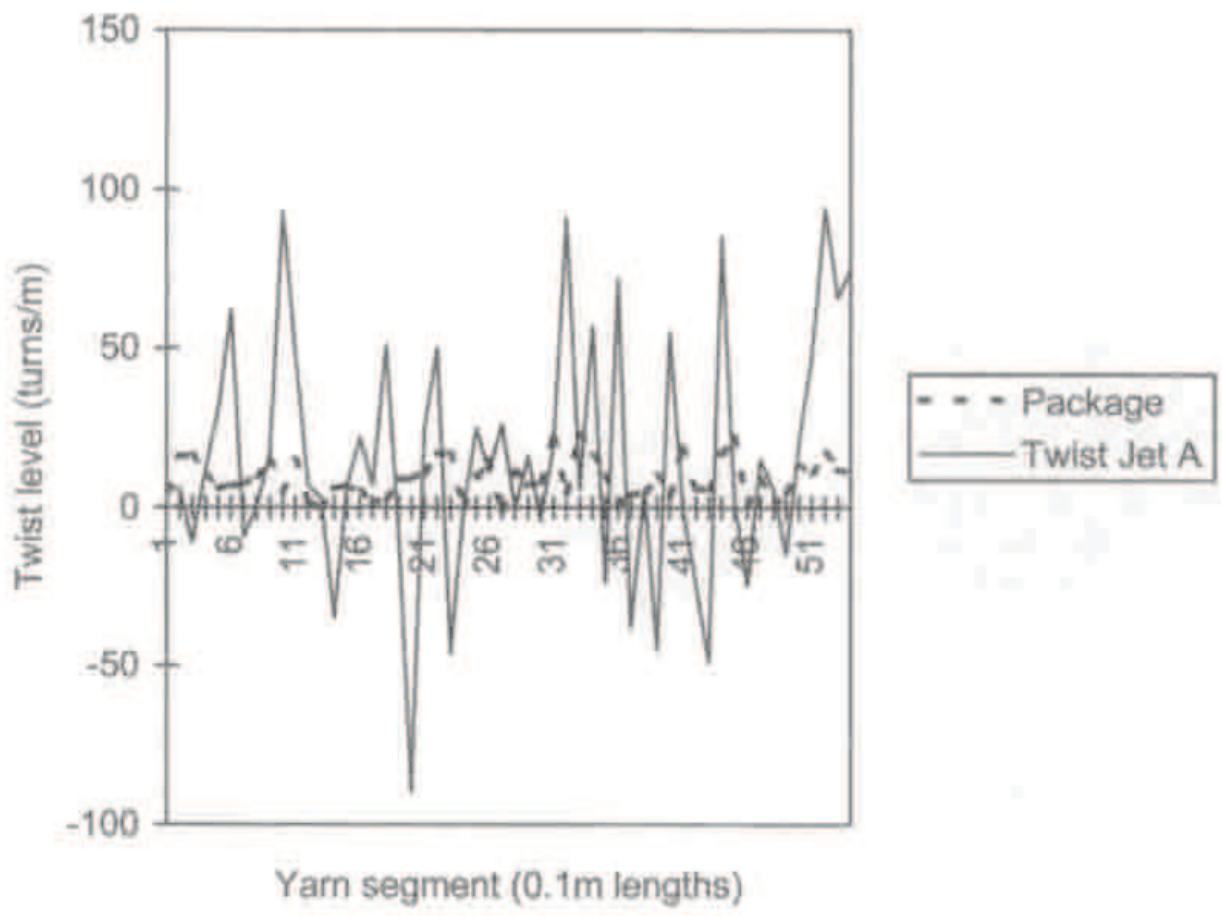

(b)

Fig. 9 Variation in twist level along yams after processing with $(a)$ no jet and $(b)$ jet A

tangential configuration but of the opposite handedness. Furthermore, the success of jet A suggests that the region of added twist might extend beyond the point of steam injection. The failure of the jet with radial inputs (jet $\mathrm{C}$ ) to increase processing times shows that neither the restriction of flow through the jet inputs, nor the shielding effect of inserting the jet between the original steam input and the yarn, contributed to the success of jet A. 


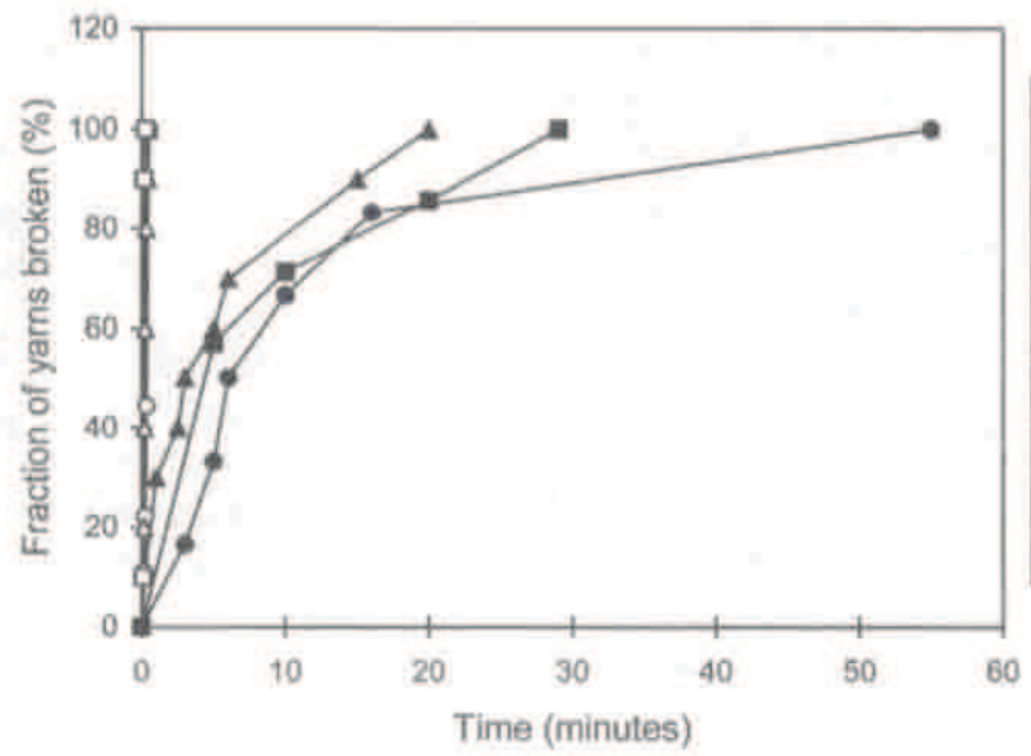

-o-No jet - Assembly 1 PC1

Jet A - Assembly I. PC1

$\rightarrow$ - Jet B - Assembly 1 PC1

-0-Jet C - Assembly I PC1

- Jet A - Assembly I. PC6

$\rightarrow-$ Jet A - Assembly IIPC6

Fig. 10 Survival times for two polyester/cotton yams under different test conditions
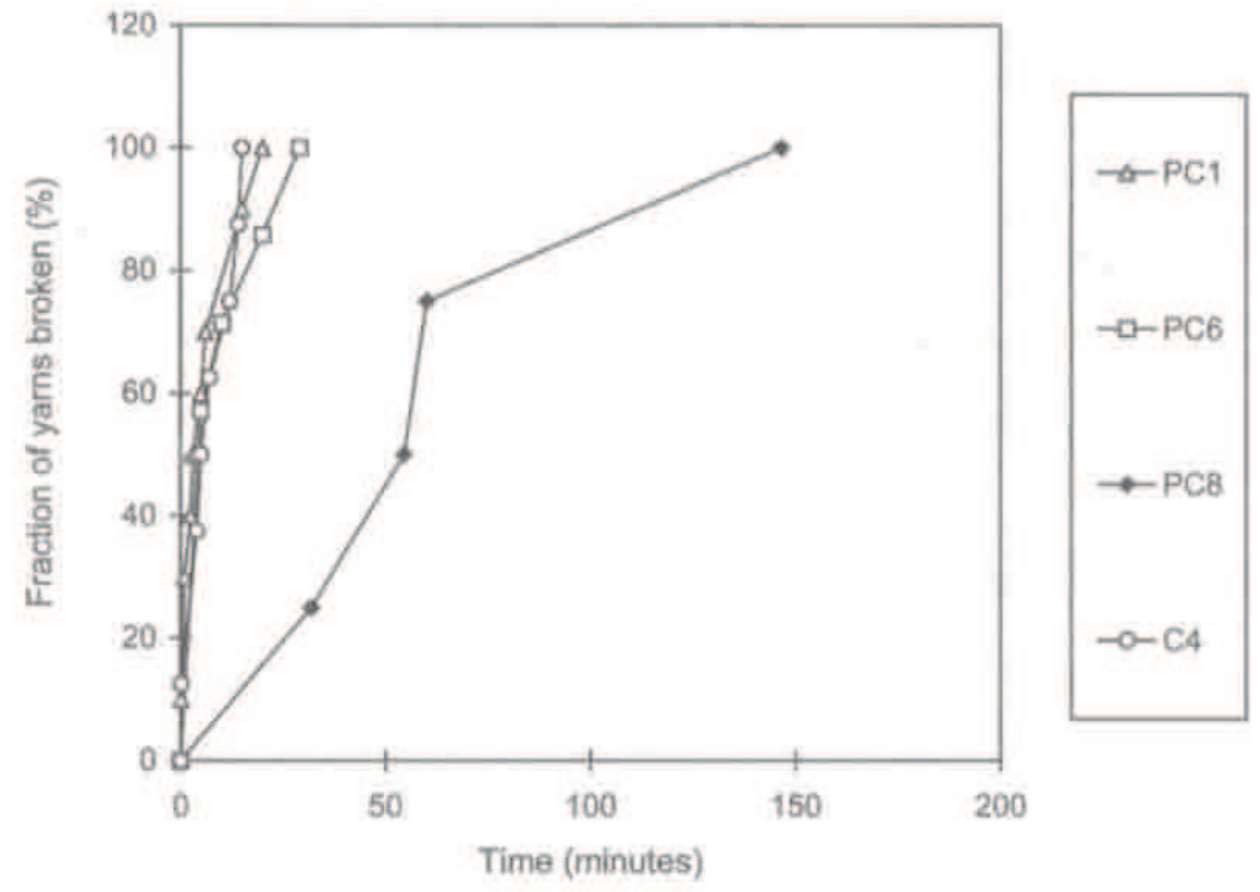

Fig. 11 Survival times for staple yams under identical test conditions

In addition to the twist jet configuration, yarn construction appears to be of importance. One open-end polyester/cotton yarn (PC8) could be processed without the use of jet A. This yarn had a minimal loss of strength when untwisted.

Further work is required before the system can be incorporated in a commercially viable dyeing system as the maximum running time before yarn failure was always less than $2 \mathrm{~h}$. Also, the performance in the presence of injected dye is unknown. However, it seems possible that these problems may be overcome by improving the evenness of the flow of yarn through the system. This should reduce twist fluctuations on the output side of the jets. 


\section{SUMMARY}

Although it has previously been shown that filament yarn can be contimuously dyed using an adaptation of the Fibre-M texturing system, there was a need to broaden the method to include staple yarns. However, the Fibre-M system was not designed for staple yam processing and early attempts proved unsuccessful. The work reported in this paper has demonstrated a method whereby staple yarn can be run in the Fibre-M system using a steam inlet reconfigured to form a tangential jet that inserts false twist.

The problem of uniform dye application for natural fibre yarns remains to be investigated. The original filament dyeing method relied on the dispersion of low molecular weight disperse dyes to achieve uniformity. This method is not applicable to other dyes and a new method must be adopted. To this end, the use of a fine aerosol to penetrate a yarn plug is reported elsewhere (Cork ef al., 1999). The next stage in the development is a programme to combine this method of application with high-speed staple processing on the adapted Fibre-M apparatus.

\section{ACKNOWLEDGEMENTS}

The authors wish to express their special thanks to M. Sumner, S. Butt, L. Downes, J. Garaghty and J.T. Jones.

\section{REFERENCES}

Chowdhury, M.D.H., 1992. Effluent-Free Yarn Dyeing. Ph.D. Thesis, UMIST, Manchester, UK.

Cork, C.R. Fuster, P.W.. Oulton, D.P., and Chowdhury, M.D.H., 1999. I. Soc. Dyers Col, 115, 333-338. Fleissener, H., and Wilhelm. E. (Vepa AG), 1972. US patent number 3835671 .

Foster, P.W., 1975. Text. Inst. Indisstr, 13, No, 6, 172-174.

Hardalov, 1., and Mikhaylova, J., 1993, J. Soc, Dyers Col., 109, 369-373.

Knittel, D, and Schollmeyer, E., 1995, Int. J. Clothing Sci, and TechnoL., 7, No. 1, 36-45.

Niederhauser, J., Devaux, 1., and Morelle, A., 1973. J. Soe. Dyers Col., 89. 533-539.

Oxenhum, W., and Basu, A., 1993, Text. Rex. J., 63, 674-678.

Rhone Poulenc Textile, 1973. UK patent number I 312579.

Saus, W.. Knittel, D., and Schollmeyer, E., 1993. Text. Res. J., 63, 135-142. 